\title{
Tip scapular free flap for complex head and neck reconstruction
}

\author{
Paolo Cariati ${ }^{1}$, Daniel Pampin Ozan ${ }^{1}$, Costantin Gonzalez Corcoles ${ }^{1}$, Susana Arroyo Rodriguez ${ }^{1}$, \\ Andrea Ferri' ${ }^{2}$, Silvano Ferrari ${ }^{2}$ \\ ${ }^{1}$ Department of Maxillofacial, Hospital General Universitario Albacete, Albacete, Spain; ${ }^{2}$ Department of Maxillofacial, Ospedale Universitario \\ Maggiore, Parma, Italy \\ Contributions: (I) Conception and design: All authors; (II) Administrative support: None; (III) Provision of study materials or patients: All authors; (IV) \\ Collection and assembly of data: P Cariati, S Ferrari; (V) Data analysis and interpretation: P Cariati; (VI) Manuscript writing: All authors; (VII) Final \\ approval of manuscript: All authors. \\ Correspondence to: Paolo Cariati, MD. Department of Maxillofacial, Hospital General Universitario Albacete, Calle Hermanos Falco, 37, 02006, \\ Albacete, Spain. Email: paolocariati1@gmail.com.
}

\begin{abstract}
Background: Reconstruction of complex head and neck defects presents a challenge for the head and neck surgeon. This is particularly true when soft tissue and skin defects are associated with the bone defect. The main aim of the present report is to describe the utility of tip scapular free flap for complex head and neck reconstruction.

Methods: The medical records of 13 patients that had undergone maxillary or mandibular reconstruction by using a free scapular tip flap were retrospectively reviewed to identify the possible advantages and disadvantages of this type of flap.

Results: Eight patients analyzed in this series underwent maxillary reconstruction with tip scapular flap, while the other five patients underwent mandibular reconstruction. No failures, partial failures, or infections were evidenced in our series. Scapular tip flap allowed for acceptable aesthetic and functional outcomes. All anastomoses were performed with the facial vessels and there was no need to use arterial or vein graft. No major complications were observed at the donor site during follow-up.

Conclusions: Scapular tip flap might be extremely useful for head and neck reconstruction. Pedicle length, versatility and reliability represent the major advantages of this reconstructive recourse. Moreover, the resistance of the scapular vascular system to atherosclerosis could be helpful in patients showing contraindications to free fibula flaps.
\end{abstract}

Keywords: Tip scapular flap; head and neck oncological reconstruction; microvascular reconstruction; thoracodorsal artery

Received: 10 July 2020; Accepted: 31 July 2020; Published: 04 September 2020.

doi: $10.21037 /$ fomm-2020-mr-05

View this article at: http://dx.doi.org/10.21037/fomm-2020-mr-05

\section{Introduction}

Reconstruction of complex head and neck defects presents a challenge for the head and neck surgeon. This is particularly true when soft tissue and skin defects are associated with the bone defect. These defects are usually reconstructed using an osteocutaneous free flap. Common reconstruction options are the fibula, iliac crest, and lateral scapula border free flap (1). However, these reconstruction options present some disadvantages, such as a short pedicle, donor site morbidity, long bedding time, and the need for numerous osteotomies to achieve a proper shape of the donor bone (2-4). Moreover, the lateral scapular border free flap requires changing the patient's posture, making it impossible for two teams to work at the same time to simultaneously ablate a tumor and harvest a flap. This problem, and the relative short pedicle, hinder the use of this reconstructive recourse (3). Despite these disadvantages, for many years, lateral scapular border free flap has been considered the quintessential scapular flap for head and neck reconstruction. However, scapular tip flap has been 


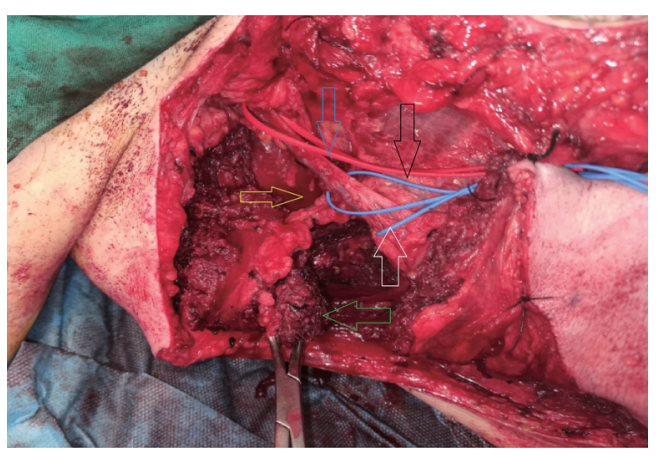

Figure 1 Clinical image showing the vascular anatomy of chimeric tip scapular flap. The blue arrow indicates the thoracodorsal artery. The yellow arrow points to the angular branch. The white and the black arrows show the branch to latissimus dorsi and serratus muscle, respectively. The green arrow indicates the tip scapular bone involved by surrounding muscles.

recently described as a reliable and effective reconstruction option for complex mandibular and maxillary defects $(5,6)$. It was first described by Deraemaeker in 1988 and offers several advantages: a long pedicle (it can reach up to $20 \mathrm{~cm}$ ), minimal donor site morbidity, and similar structure to the native maxilla and mandibular angle (7). Moreover, the vessels of the scapular vascular system are extremely resistant to atherosclerosis and can be used safely even in patients with pathologies of the peripheral vascular system. Despite these benefits, several authors have described the necessity to change the patient's posture to obtain a tip scapular flap (8). The main aim of the present report is to describe the utility of tip scapular free flap for complex head and neck reconstruction. Importantly, two teams worked simultaneously in 11 of 13 patients included in this study. This significantly contributed to reduce the surgical time. We present the following article in accordance with the MDAR Reporting Checklist (available at https://fomm.amegroups. com/article/view/10.21037/fomm-2020-mr-05/rc).

\section{Methods}

The medical records of 13 patients who had undergone maxillary or mandibular reconstruction by using a microvascular scapular tip flap were retrospectively reviewed to identify possible advantages and disadvantages of this type of flap. Failure or partial failure, aesthetic outcomes, and early and late complications were analyzed. All reconstructions were performed between November 2017 and March 2020.
Our institutions don't require ethical approval for retrospective studies. A written consent was signed by all patients.

\section{Anatomy}

Harvesting the scapular tip involves resecting a portion of the infraspinatus, subscapularis, teres major, the insertion of the serratus, and, if a skin paddle is needed, dissection and harvesting of the latissimus dorsi flap. Several of these muscles are part of the rotator cuff, which stabilizes the glenohumeral joint. The rotator cuff is formed by the supraspinatus and infraspinatus, teres minor, teres major, and subscapularis. Vascularization of the scapular tip is provided by the angular artery that arises from the thoracodorsal artery (Figure 1). Innervation is provided by the thoracodorsal nerve that runs along the pedicle to the latissimus muscle (8). During flap harvesting, it is important to avoid sacrificing this nerve because it is helpful to define the direction and the dissection of the pedicle. The study was conducted in accordance with the Declaration of Helsinki (as revised in 2013). Our institutions don't require ethical approval for retrospective studies and individual consent for this retrospective analysis was waived.

\section{Results}

Eight patients analyzed in this series underwent maxillary reconstruction with tip scapular flap, while the other five patients underwent mandibular reconstruction. Reconstruction was performed in eight patients for squamous cell carcinoma, in three patients for osteoradionecrosis, in one patient for inadequate aesthetic result after previous hemi-maxillectomy and reconstruction with temporalis flap and in another patient for recurrent keratocyst. In 11 of the 13 cases, two teams worked at the same time to perform ablation and flap harvesting simultaneously. Reconstruction was performed by using bone, muscle, and skin in five patients, only bone in five patients, and bone and muscle in three patients. No flap failure or infection were evidenced in our series. All flaps showed a complete epithelization between 31 and 83 days. All anastomoses were performed with the facial vessels. No arterial or vein grafts were used. The donor site was primary closed in all cases. No major complications were observed at the donor site during followup. The average hospital stay was approximatively 11 days. Aesthetic outcomes were considered to be good in eight patients and fair in five (Figure 2). 

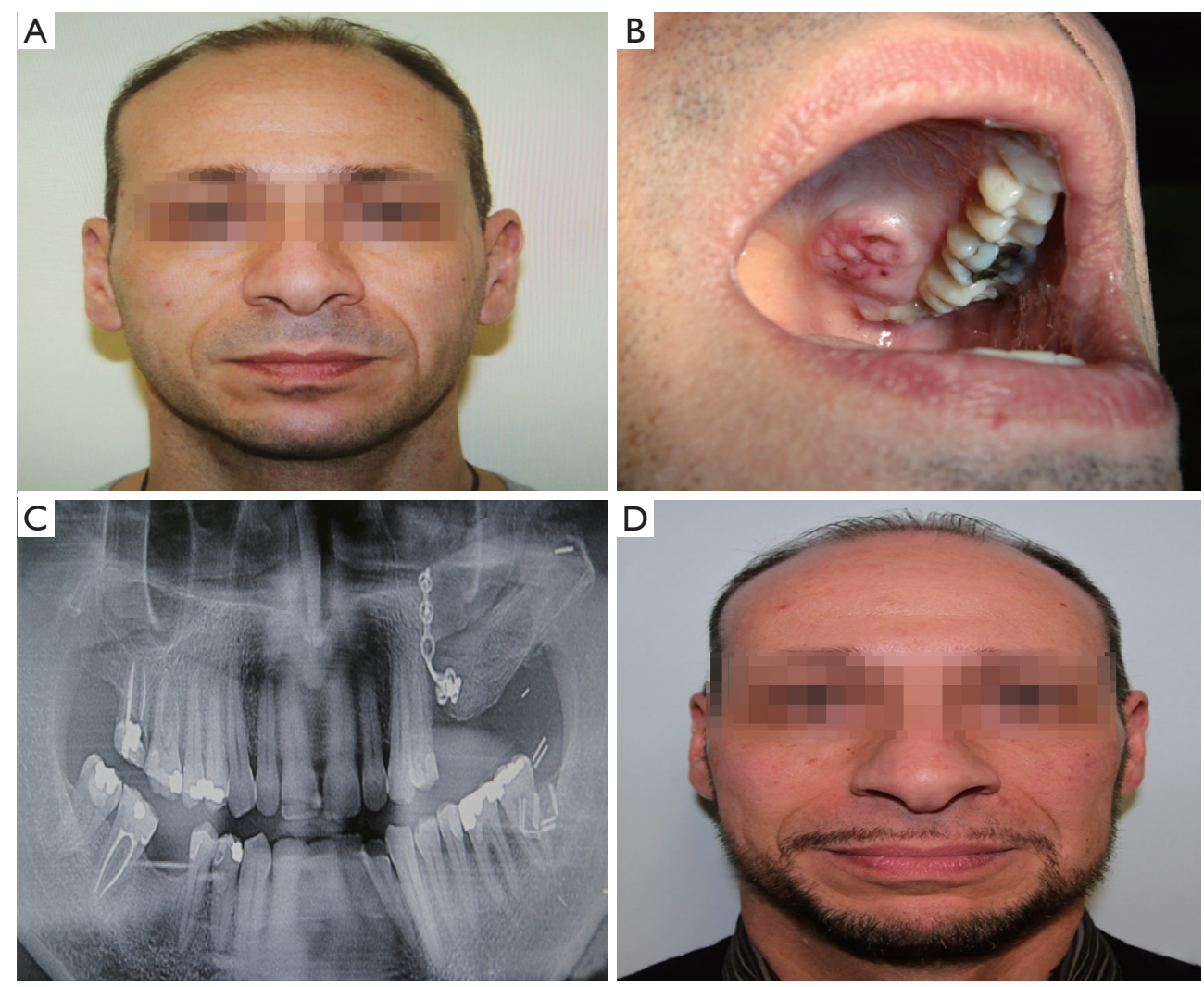

Figure 2 Patient 2: a 47-year-old male with adenoid cystic carcinoma of the hard palate. (A) Patient before surgery; (B) clinical image showing the lesion affecting the left hard palate; (C) postoperative OPG showing the horizontal insertion of tip scapular bone to reconstruct the palatal defect; (D) patient after surgery.

\section{Discussion}

The reliability, utility, and effectiveness of scapular tip free flap for head and neck reconstruction have been described by several authors in recent years (9). The main advantages of this reconstructive recourse are: a long pedicle (up to $20 \mathrm{~cm}$ ), easy bone remodeling without the need for numerous osteotomies, low morbidity at the donor area, a chimeric option, and abundant soft tissue availability $(5,8,10)$. In this regard, this flap offers a more considerable availability of tissue when compared with fibular or iliac crest flap and it might be extremely useful in cases of extensive soft tissue loss (Figure 3). Moreover, each part of the flap (bone, latissimus dorsi muscle with skin, and anterior serratus) receives an independent pedicle with mobile tissue components; thus, it can be easily mobilized and placed according to reconstructive needs. This feature notably facilitates the flap inset. In addition, the scapular tip is very similar to the maxilla (6). The flap may be oriented vertically or horizontally, a factor that allows for efficient reconstruction of several types of maxillary defects (Figures 2,4). The entire hemi-maxilla-including the orbital floor and the palate-might be completely reconstructed if the flap is positioned vertically. Moreover, the flap can reproduce the entire palato-alveolar complex when it is oriented horizontally. It is also important to note that tip scapular flap is a reliable reconstructive recourse for mandibular reconstruction, especially in the case of neck depletion vessel. In fact, the length of the pedicle usually allows the surgeon to reach the transverse cervical artery, which is not usually sacrificed in most of the neck dissection. Moreover, the scape of the tip scapular bone is very similar to the mandibular angle (11). In the case of reconstruction of mandibular symphysis, a greenstick fracture of the tip scapular bone allows the surgeon to properly recreate the mandibular contour. In addition, this flap allows the insertion of osseointegrated implants.

However, the patient's posture might need to change after finishing ablative surgery with the conventional 

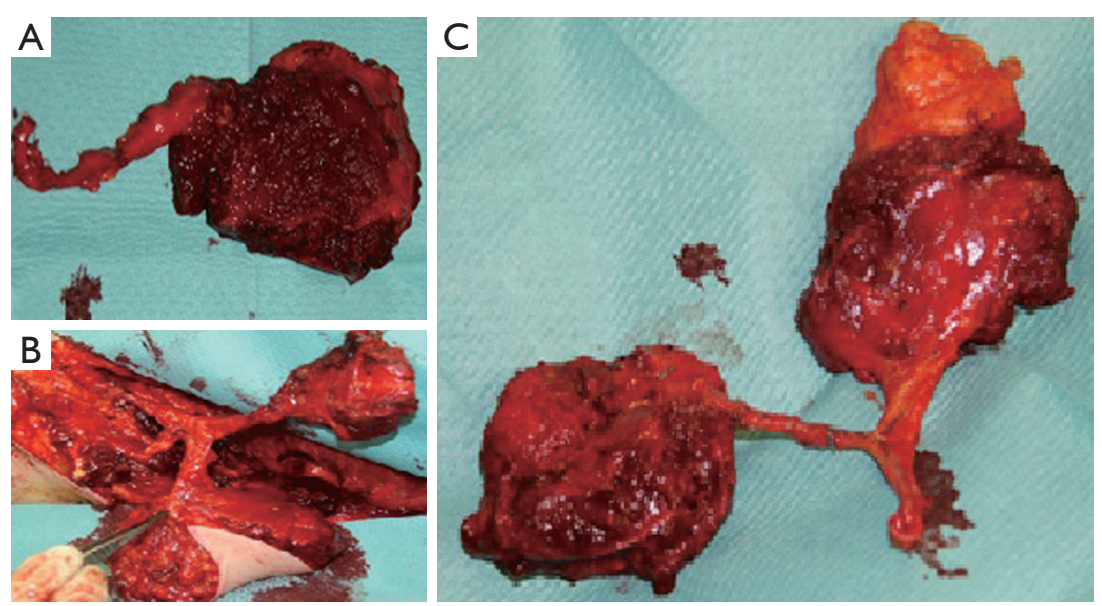

Figure 3 Clinical image showing the reconstruction options offered by tip scapular flap. (A) Bony flap; (B) bone + muscle; (C) bonemyocutaneous.

harvest technique (8). This change might notably lengthen surgical times. According to several authors, this is the main disadvantage presented by this flap. Our surgical approach allows two surgical teams to work at the same. To place the patient in the supine position with the arm completely abducted and the hand span upward is the key to our technique. The arm position can be secured by an assistant or with the use of an armrest. The use of an armrest is particularly helpful because it avoids inopportune mobilizations secondary to the fatigue of the assistant who holds the arm. Therefore, this patient position guarantees a significant reduction in surgical time. It is important to highlight that when flap harvesting and ablative surgery were performed at the same time, the tip scapular bone contralateral to the tumor side was used for the reconstruction. This approach significantly facilitates two team working at the same time without space conflicts. In addition, remodeling and fixation of a tip scapular flap is generally fast and easy. Consequently, surgical times are shorter compared to fibula flap, DCIA, and lateral scapula border free flap. In fact, the bone can be greenstickfractured to guarantee a proper set-in and adequate projection. In contrast to the fibula, no further osteotomies need to be performed for a proper flap insertion. The fixation of the scapular bone may be accomplished with the use of miniplates or wire.

Another tip to facilitate flap harvesting is the use of a bone forceps to mobilize the scapula. This surgical tool allows the surgeon to mobilize the bone upward and downward and significantly facilitates the disinsertion of the parascapular muscles and the osteotomy (10). It is also very important to relax the patient as much as possible. This factor will also be extremely useful to facilitate bone mobilization and the disinsertion of parascapular muscles. Another important advantage of the scapular tip flap is that surgeon can take only the amount of bone needed for reconstruction. This factor is particularly important in the presence of small defects. However, this approach is not possible when fibula flap is used. In fact, a significant part of the fibula bone needs to be resected to obtain a sufficient length of the pedicle, even in cases of small defects.

No patient analyzed in this series showed significant complications during the postoperative period. According to several authors, morbidity of tip scapular flap at the donor site is comparable with the morbidity of neck dissection $(5,12)$. In fact, complete shoulder recovery was evidenced during the first six month after surgery in all patients analyzed in this study. Moreover, this flap is particularly useful in elderly patients for several reasons $(10,11,13)$. First, the rapid mobilization of the patients during the early postoperative period accelerates the recovery and significantly shortens the hospital stay. Second, the vessels of the scapular vascular system are extremely resistant to atherosclerosis and can be used safely even in patients with pathologies of the peripheral vascular system in which fibula free flap is contraindicated.

\section{Conclusions}

For all these reasons, tip scapular flap is considered a reliable, feasible, and extremely useful resource for 

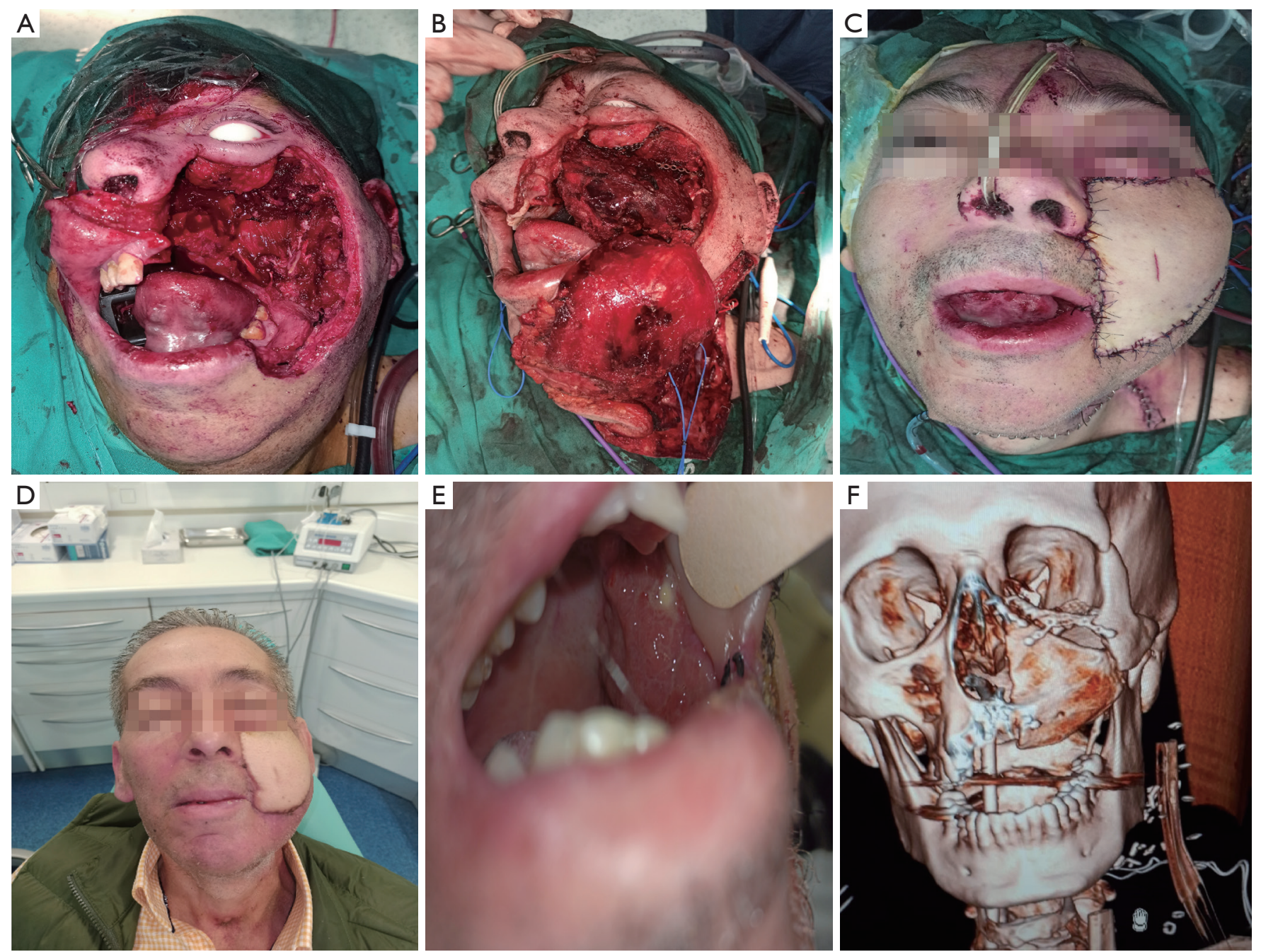

Figure 4 Patient 1: a 51-year-old male with squamous cell carcinoma of the left maxillary sinus. (A) extensive defect after ablative surgery; (B) clinical image showing the vertical insertion of tip scapular bone for the reconstruction of the orbital floor and left maxilla; (C) clinical image showing the great coverage offered by latissimus dorsi muscle; (D) patient 3 months after surgery; (E) clinical image showing the intraoral appearance of the reconstruction; (F) CT scan showing the vertical insertion of tip scapular bone.

maxillary and mandibular reconstruction. The possibility of simultaneously performing flap harvesting and ablative surgery adds another important advantage and will facilitate the spread and use of this type of flap. In our opinion, tip scapular flap should be regarded as an essential reconstructive resource of each head and neck reconstructive surgeon. The major limitations of this study are its retrospective character and the small sample size.

\section{Acknowledgments}

Funding: None.

\section{Footnote}

Provenance and Peer Review: This article was commissioned by the Guest Editor (Paolo Cariati) for the series "Microvascular reconstruction of head and neck oncological defects-state of the art" published in Frontiers of Oral and Maxillofacial Medicine. The article has undergone external peer review.

Reporting Checklist: The authors have completed the MDAR reporting checklist. Available at https://fomm.amegroups. com/article/view/10.21037/fomm-2020-mr-05/rc 
Data Sharing Statement: Available at https://fomm.amegroups. com/article/view/10.21037/fomm-2020-mr-05/dss

Conflicts of Interest: All authors have completed the ICMJE uniform disclosure form (available at https://fomm. amegroups.com/article/view/10.21037/fomm-2020-mr-05/ coif). The series "Microvascular reconstruction of head and neck oncological defects-state of the art" was commissioned by the editorial office without any funding or sponsorship. PC served as the unpaid Guest Editor of the series and serves as an unpaid editorial board member of Frontiers of Oral and Maxillofacial Medicine from Apr 2020 to Mar 2022. The authors have no other conflicts of interest to declare.

Ethical Statement: The authors are accountable for all aspects of the work in ensuring that questions related to the accuracy or integrity of any part of the work are appropriately investigated and resolved. The study was conducted in accordance with the Declaration of Helsinki (as revised in 2013). Our institutions don't require ethical approval for retrospective studies and individual consent for this retrospective analysis was waived.

Open Access Statement: This is an Open Access article distributed in accordance with the Creative Commons Attribution-NonCommercial-NoDerivs 4.0 International License (CC BY-NC-ND 4.0), which permits the noncommercial replication and distribution of the article with the strict proviso that no changes or edits are made and the original work is properly cited (including links to both the formal publication through the relevant DOI and the license). See: https://creativecommons.org/licenses/by-nc-nd/4.0/.

\section{References}

1. Dowthwaite SA, Theurer J, Belzile M, et al. Comparison of fibular and scapular osseous free flaps for oromandibular reconstruction: a patient-centered approach to flap selection. JAMA Otolaryngol Head Neck Surg 2013;139:285-92.

2. Choi N, Cho JK, Jang JY, et al. Scapular Tip Free Flap for Head and Neck Reconstruction. Clin Exp Otorhinolaryngol 2015;8:422-9.

3. González-García R, Naval-Gías L, Rodríguez-Campo FJ, et al. Vascularized free fibular flap for thereconstruction of mandibular defects: clinical experience in 42 cases. Oral Surg Oral Med Oral Pathol Oral Radiol Endod 2008;106:191-202.

4. Brown JS, Jones DC, Summerwill A, et al. Vascularized iliac crest with internal oblique muscle for immediate reconstruction after maxillectomy. Br J Oral Maxillofac Surg. 2002;40(3):183-90.

5. Clark JR, Vesely M, Gilbert R. Scapular angle osteomyogenous flap in postmaxillectomy reconstruction: defect, reconstruction, shoulder function, and harvest technique. Head Neck 2008;30:10-20.

6. Pagedar NA, Gilbert RW, Chan H, et al. Maxillary reconstruction using the scapular tip free flap: a radiologic comparison of 3D morphology. Head Neck 2012;34:1377-82.

7. Van Thienen CE, Deraemaecker R. The Serratus Anterior Scapular FlapA New Osteomuscular Unit. Eur J Plast Surg 1988;11:156-61.

8. Chepeha D, Khariwala S, Chanowski E, et al. Thoracodorsal artery scapular tip autogenous transplant: vascularized bone with a long pedicle and flexible soft tissue. Arch Otolaryngol Head Neck Surg 2010;136:958-64.

9. Wagner A, Bayles $\mathrm{S}$. The angular branch: maximizing the scapular pedicle in head and neck reconstruction. Arch Otolaryngol Head Neck Surg 2008;134:1214-7.

10. Ferrari S, Ferri A, Bianchi B. Scapular tip free flap in head and neck reconstruction. Curr Opin Otolaryngol Head Neck Surg 2015;23:115-20.

11. Bianchi B, Ferri A, Ferrari S, et al. Reconstruction of mandibular defects using the scapular tip free flap. Microsurgery 2015; 35:101-6.

12. Patel KB, Low TH, Partridge A, et al. Assessment of shoulder function following scapular free flap. Head Neck 2020;42:224-9.

13. Yeh DH, Lee DJ, Sahovaler A, et al. Shouldering the load of mandible reconstruction: 81 cases of oromandibular reconstruction with the scapular tip free flap. Head Neck 2019;41:30-6.

doi: 10.21037/fomm-2020-mr-05

Cite this article as: Cariati P, Pampin Ozan D, Gonzalez Corcoles C, Arroyo Rodriguez S, Ferri A, Ferrari S. Tip scapular free flap for complex head and neck reconstruction. Front Oral Maxillofac Med 2020;2:19. 